\title{
O comércio civiliza, Portugal oprime \\ a História do Brasil de John Armitage e a linguagem do humanismo comercial*
}

\section{The commerce civilize, Portugal oppresses the History of Brazil by John Armitage and the language of commercial humanism}

\author{
FLÁVIA FLORENTINO VARELLA** \\ Departamento de História \\ Universidade Federal do Rio Grande do Sul \\ Porto Alegre (RS) \\ Brasil
}

RESUMO O principal objetivo deste artigo consiste em apresentar a linguagem do humanismo comercial como horizonte historiográfico interpretativo para John Armitage na escrita de sua História do Brasil, publicada em 1836. Esta linguagem é definida por John Pocock como a junção dos conceitos de virtude e comércio, os quais compunham vocabulários políticos opostos antes do século XVIII, no intuito de formar uma nova linguagem em que a esfera do social adquiriu centralidade. Nesse sentido, o desenvolvimento das virtudes desse novo homem social deveria ser dado justamente no contato com pessoas e coisas propiciado pelo comércio. Armitage tendeu a caracterizar a história nacional brasileira como o inverso do que seria a história de uma sociedade comercial, principalmente pela restrição comercial que enfrentava

\footnotetext{
* Artigo recebido em: 05/03/2012. Aprovado em: 03/06/2012.

** Este artigo é parte da minha dissertação de mestrado defendida no Programa de Pós-Graduação em História Social da Universidade de São Paulo, sob a orientação do Prof. Dr. João Paulo Garrido Pimenta e com financiamento da Coordenação de Aperfeiçoamento de Pessoal de Nível Superior (CAPES). Contato: flavia_varella@hotmail.com.
} 
e pela falta de estímulo de Portugal, tido como um país estagnado. Aliado a isso, Armitage também apresenta a figura de D. Pedro I como propícia a fomentar guerras ao invés de estimular o comércio e as interações sociais.

Palavras-chave história da historiografia, historiografia imperial, linguagem historiográfica

ABSTRACT The main goal of this paper is to present how the language of commercial humanism can be a keyword to understand the John Armitage's History of Brazil written in 1836. This language is defined by John Pocock as a combination between the concepts of virtue and commerce, which were in distinct political vocabulary until the $18^{\text {th }}$ century, in order to form a new language in which the social sphere has become central. In this sense, the development of virtues of the new social man should be given precisely in contact with people and things in trade relations. Armitage has tended to characterize the Brazilian national history as the inverse of what would be the story of a commercial society mainly because the trade restrictions it was faced and the lack of stimulation by Portugal, a stagnated country. As such, it presents D. Pedro I having a propensity to foment wars instead of stimulating trade and social interactions.

Keywords history of historiography, imperial historiography, historiographical language

\section{Introdução}

A Grã-Bretanha encontrou na afirmação do livre comércio entre as nações e na difusão de seus ideais por meio das relações comerciais o ponto chave que iria lhe garantir a dominação de parte de todos os seis continentes até finais do século XIX. Dentre todos os continentes considerados integrantes do novo mundo, a parte sul da América foi aquela em que a Grã-Bretanha alcançou a menor expansão territorial. No que diz respeito ao cenário brasileiro, essa lacuna viria a ser, de certa forma, compensada através da inserção de produtos ingleses e do estabelecimento de suas instituições financeiras e comerciais. A História do Brasil de que vamos tratar ao longo deste artigo foi publicada em 1836, originalmente em inglês, pelo comerciante John Armitage, nascido na pequena cidade de Failsworth aos 27 de setembro de 1807. Sua família seguia a doutrina unitária ${ }^{1}$ e partici-

1 O unitarismo surgiu como uma ramificação do presbiterianismo, diferenciando-se por acreditar na unidade de Deus e, principalmente, por não acreditar na trindade e na morte de Cristo como um sacrifício ou uma expiação dos pecados da humanidade. Maiores detalhes sobre as crenças unitárias e sua interligação com a llustração, cf. SOARES, Luiz Carlos. Do presbiterianismo ao unitarismo: a trajetória dos dissidentes racionalistas ingleses. 
pava do círculo dos comerciantes não conformistas de Manchester, o que provavelmente Ihe rendeu a proposta de representar a firma Philips, Wood \& Co. ${ }^{2}$ na cidade do Rio de Janeiro, em 1828.

Não existem muitos registros de suas atividades durante os sete anos que permaneceu no Brasil. Sabemos que escreveu um poema inspirado nas belezas do Rio de Janeiro, do qual resta apenas um fragmento, ${ }^{3}$ e que foi admitido como membro da Sociedade Defensora da Liberdade e Independência Nacional (1831-1835) na sessão de 17 de novembro de 1831. ${ }^{4}$ Sua admissão se deu, muito provavelmente, graças a sua amizade com Evaristo da Veiga, um dos fundadores dessa Sociedade. ${ }^{5}$

Retornou à Inglaterra no dia 6 de julho de $1835^{6}$ - aos 27 anos - e publicou, em 1836, a History of Brazil, em dois volumes, que foi contemplada com excelente tradução para a língua portuguesa no ano seguinte. ${ }^{7}$ Aceitando um convite que considerava como irrecusável, Armitage embarcou logo

In: . A albion revisitada: ciência, religião, ilustração e comercialização do lazer na Inglaterra do século XVIII. Rio de Janeiro: 7Letras/FAPERJ, 2007, p.69-80.

2 É extremamente difícil precisar quais os artigos vendidos no mercado luso-brasileiro por esta firma e seus representantes; o certo é que figuraram como fabricantes de chapéus e comerciantes de produtos químicos e corantes. A família Philips dedicou-se, por longos anos, a atividades comerciais diversas e integrou os grupos comerciais não conformistas de Manchester. Na primeira parte do século XIX, além da Philips, Wood and Co., estavam em atividade a Samuel Philips \& Co. - sediada também em Manchester e fabricante de tecidos pesados -; Philips, Lee \& Co. - em Salford e envolvidos na fiação do algodão; George Philips \& Co. - em Londres, como comerciantes; e Philips, Cramond \& Co. - na Filadélfia, também como comerciantes CHAPMAN, Stanley. Merchant enterprise in Britain: from Industrial Revolution to World War I. Cambridge: Cambridge University Press, 2003, p.64. Devido ao reconhecimento dos integrantes dessa família como comerciantes bem sucedidos, George Philips foi eleito Membro do Parlamento de 1830 a 1852, seu irmão Mark Philips de 1832 a 1847 e Robert Needham Philips de 1857 a 1885; vide: CHAPMAN, Stanley. Merchant enterprise in Britain, p.66. Apenas a titulo de ilustração, esclarecemos que as inicias M.P., inscritas na dedicatória da História do Brasil, referem-se justamente ao título de Membro do Parlamento que Mark Philips tinha em 1836

3 Transcrevemos o fragmento a seguir:

"Within the shores of that far southern land,

Where 'erst the Indian wander'd wild and free,

A mighty city proudly gems the strand

And of an empire claims the sovereignty.

Oh! lovely is the landscape ye may see,

Where Rio's turrets, cliffs, and convents white,

Stand on the margin of the azure sea!"

Cf. The Christian Reformer or unitarian magazine and review. New series, v.XIL. From January to December. London: Edward T. Whitfield, 1856, p.318.

4 GUIMARÃES, Lucia Maria Paschoal. Em nome da ordem e da moderação: a trajetória da Sociedade Defensora da Liberdade e da Independência Nacional do Rio de Janeiro (1831-1835). Rio de Janeiro: Universidade Federa do Rio de Janeiro, 1990, p.78, nota 73 (História, Dissertação de mestrado); cf. Aurora Fluminense, n.17 de 11 fev. 1832

5 SOUSA, Octávio Tarquínio de. Evaristo da Veiga. São Paulo: Companhia Editora Nacional, 1939, p.304

6 RODRIGUES, José Honório. (org.). Registro de estrangeiros, 1831-1839. Rio de Janeiro: Ministério da Justiça e Negócios Interiores, Arquivo Nacional, 1962, p.16.

7 É importante ressaltar algumas nuances entre as edições da História do Brasil publicadas em português. A primeira edição da obra, publicada em 1837 pela Tipografia Imperial de J. Villeneuve e Comp., trouxe ao público de língua portuguesa todo o conteúdo da edição original em inglês, exceto as duas litografias de Evaristo da Veiga e José Bonifácio, que foram substituídas por outras de estilo mais "romântico". Foram acrescidas a esta primeira edição brasileira as litografias de D. Pedro I e Bernardo Pereira de Vasconcelos, que não constavam na edição inglesa. A edição que citamos ao longo deste trabalho foi publicada pela editora Itatiaia e pela Edusp em 1981. Tal edição constitui-se como a mais fidedigna que possuímos em língua portuguesa, apesar de não trazer nenhuma das duas litografias publicadas na edição inglesa. Algumas edições em língua portuguesa excluíram partes consideráveis da obra de Armitage, sendo o exemplo mais crítico disso a produzida pela editora Melhoramentos, na qual todas as notas de rodapé foram suprimidas sem nenhum aviso aos leitores; cf. ARMITAGE, João. História do Brasil. São Paulo: Melhoramentos, 1977. Assim, temos diferentes edições da obra publicadas no Brasil, mas apenas uma tradução, que é a de 1837. 
em seguida a sua chegada para a cidade de Colombo, situada na possessão britânica do Ceilão (atual Sri Lanka), para atuar nessa cidade como representante de outra companhia mercantil. De fato, essa oportunidade acabou sendo o ponto de partida para, alguns anos depois, a abertura de suas próprias firmas comerciais. ${ }^{8}$ Aliado às atividades mercantis, Armitage também foi plantador de café no Ceilão, ${ }^{9}$ atuou como membro do Conselho Legislativo entre 8 de maio de $1840^{10}$ e 22 de agosto de $1855^{11}$ e foi membro fundador da Câmara de Comércio, ${ }^{12}$ criada em 25 de março de 1839.

A trajetória de vida de Armitage esteve diretamente ligada aos ideais de comércio e civilização do Império Britânico em todas as esferas que atuou, seja como comerciante, funcionário da coroa ou mesmo historiador. Não foi apenas um comerciante, no sentido estrito do termo, mas um comerciante inglês preocupado em desvendar terras distantes que se mostravam como excelentes parceiros comerciais, assim como uma oportunidade civilizacional irresistível.

Objetivamos demonstrar que sua História do Brasil não apenas traça o desenrolar da história brasileira desde 1808 até a abdicação de D. Pedro I, mas a história de um país oprimido pela mãe pátria invejosa do filho próspero. No intuito de legitimar seu relato do impasse entre dois registros de conduta, o britânico e o português, Armitage utilizou-se da linguagem do humanismo comercial como horizonte historiográfico interpretativo de sua narrativa. Acreditava que existia um movimento distinto entre a política de gerência das colônias britânicas e portuguesas já que enquanto a GrãBretanha enviava seus súditos para suas possessões no sentido de tornar suas colônias mais prósperas e polidas, Portugal não acreditava no livre comércio e na interação gerada pela sua expansão territorial. ${ }^{13}$

Do ponto de vista britânico, essa expansão não se daria apenas no horizonte comercial, já que as pessoas teriam a oportunidade de consumir produtos diversos, mas também de entrar em contato com costumes e pessoas diferentes, ocasionando uma mudança na dinâmica da sociedade. Em uma perspectiva que imaginava ser totalmente distinta da portuguesa, Armitage acreditava que somente a partir da interação entre pessoas e

8 Armitage manteve, em épocas distintas, duas firmas em Colombo: a Armitage, Scott \& Co. e a Armitage Brothers. Cf. National Archives of the United Kingdom. John Armitage last Will and testament. PROB 11/2238, p.674.

9 Essa informação está escrita, à caneta, na página de rosto do primeiro volume da History of Brazil (primeira edição) que se encontra no Tameside Local Studies, em Ashton-under-Lyne, UK. O exemplar em questão pertenceu a Daniel Fowler Howorth que levantou tal informação através de pesquisas genealógicas.

10 ACCOUNTS and papers. Colonies, v.31, p.164, feb. -9 aug. 1845.

11 Em seu lugar foi nomeado o Capitão Henry Charles Bird. Cf. Hampshire telegraph and sussex chronicle. Portsmouth, p.8, Saturday, 15 dec. 1855

12 A Câmara de Comércio do Ceilão existe até os dias de hoje. Disponível em: < http://www.chamber.lk> Acesso em 12/07/2012.

13 Maria Odila da Silva Dias destaca que "as vantagens civilizadoras do comércio, diversificando as necessidades, estimulando o convívio, a vizinhança cordial, as comunicações do interior com o litoral e a integração da colônia na moderna civilização ocidental" já eram pontos ressaltados na História do Brasil do inglês Robert Southey, publicada entre os anos de 1810 e 1819. Cf. DIAS, Maria Odila da Silva. O fardo do homem branco: Southey, historiador do Brasil. São Paulo: Companhia Editora Nacional, 1974, p.4-5. 
coisas é que seria possível ao Brasil superar os males causados pela forma que foi colonizado e, assim, superar as limitações de uma colonização que visava mais mantê-lo inerte que despertar suas vocações.

\section{A História do Brasil e o humanismo comercial}

A linguagem do humanismo comercial ${ }^{14}$ surgiu como horizonte explicativo do grau de desenvolvimento civilizacional das nações a partir de finais do século XVIII. Dentro desse vocabulário, o comércio era tido como elemento central para promover a expansão cultural e o refinamento das maneiras através da intensificação do contato dos homens com as pessoas e as coisas produzidas. John Armitage aponta em sua História do Brasil como a colonização portuguesa, principalmente antes de 1808, dificultou a consolidação de uma sociedade comercial no Brasil por meio de iniciativas que não valorizavam o comércio entre as diversas partes do globo e pela manutenção de práticas denominadas como "cavalheirescas". Salienta que ao invés de Portugal estimular o desenvolvimento das sociabilidades modernas em sua colônia, teria privilegiado uma colonização baseada na inveja dos progressos brasileiros e restrita do ponto de vista mercantil.

Segundo as análises de John Pocock, o surgimento da linguagem do humanismo comercial teria ocorrido através do embate entre a tradição do humanismo cívico e do modo jurídico de se discursar sobre a política. Essas duas tradições discursivas articulavam, separadamente, os vocabulários da linguagem da virtude republicana, associada diretamente ao conceito de virtude, e da linguagem da jurisprudência, ligada ao conceito de comércio. Por um lado, o conceito de virtude esteve associado ao humanismo cívico, em que o vivere civile tornava o homem cidadão, preocupado com a realização do bem público na esfera política. O republicanismo cívico, assim, dava um destaque maior ao plano da política, já que era "orientado para as relações pessoais não mediadas, implicadas pela igualdade e pelo governar e ser governado". ${ }^{15}$ Por outro lado, o conceito de comércio se inseria dentro do vocabulário da jurisprudência, que mantinha seu foco no que era possível de ser distribuído - as coisas e os direitos - em oposição à virtude, que não poderia ser reduzida nem a um direito, nem ser distribuída. A jurisprudência preocupava-se com o social principalmente por ser o plano aventado em que as coisas poderiam ser administradas e distribuídas e no qual as reações humanas se davam por mediação das coisas. ${ }^{16} \mathrm{~A}$ linguagem do humanismo comercial teria sido construída por causa da necessidade insurgente

14 O tradutor do Linguagens do ideário político, de John Pocock, optou por traduzir "commercial humanism" como humanismo mercantilista, contudo achamos que humanismo comercial indica melhor o que Pocock pretendia dizer. Por isso, adotamos a nomenclatura humanismo comercial, ao invés de humanismo mercantilista.

15 POCOCK, John. Linguagens do ideário político. São Paulo: EDUSP, 2003, p.91.

16 POCOCK, John. Linguagens do ideário político, p.91. 
de compatibilizar virtude e comércio, sem que isso levasse fatalmente à corrupção do cidadão, que precisava ao mesmo tempo ser autônomo e prover sua autonomia por meio do comércio.

Com a aproximação entre virtude e comércio, o primeiro conceito sofreu uma redefinição e começou a atender pelo nome de "maneiras". Na medida em que o mundo medieval foi deixando de existir, pela inserção do comércio no dia a dia das pessoas, as relações e interações dos seres sociais com os outros e com as coisas foi se tornando mais complexa e desenvolvendo diversos aspectos da personalidade do indivíduo. Esse novo tipo de relação era:

De natureza social e não política, as capacidades que elas levavam o indivíduo a desenvolver não eram chamadas de 'virtudes', mas de 'maneiras' (...). A psicologia social da época afirmava que encontros com coisas e pessoas evocavam paixões e as refinavam, transformando-as em maneiras. Era preeminente a função do comércio refinar as paixões e polir as maneiras. ${ }^{17}$

Nesse tipo de sociedade comercial, a virtude foi redefinida como prática e refinamento das maneiras e o homem especulativo "não devia ser escravo de suas paixões, ele tinha de moderá-las, convertendo-as em opinião, experiência e interesse", em um sistema de laços sociais que reforçavam

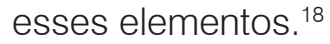

A centralidade do comércio como fator de expansão cultural e possibilidade de refinamento das paixões, dado por meio do contato com as pessoas e coisas, são aspectos do vocabulário do humanismo comercial, de fins do século XVIII, extremamente relevantes para entender o horizonte linguístico disponível para John Armitage na época em que escrevia a História do Brasil. A ampliação do Império Britânico apropriou-se e modificou esse vocabulário por meio da incorporação de novos elementos a essa linguagem. A expansão comercial certamente foi o componente sustentador da construção do Império Britânico, a qual permitiu à Inglaterra ser o entreposto para o mundo. ${ }^{19}$ Essa rede comercial também teve o mérito de auxiliar o encontro entre pessoas de lugares e, até mesmo, de continentes distintos e fazer com que o tipo de experiência entre pessoas e coisas do humanismo comercial fosse multiplicado entre seus participantes.

A esfera do social seria o espaço por excelência em que o cidadão poderia entrar em contato com as pessoas e as coisas, na tentativa de polir suas maneiras. ${ }^{20}$ Para Armitage, os portugueses e seus descendentes

17 POCOCK, John. Linguagens do ideário político, p.97.

18 POCOCK, John. Linguagens do ideário político, p.155.

19 PORTER, Andrew. Introduction. In: PORTER, Andrew (ed.). The Oxford History of British Empire. v.3: The nineteenth century. Oxford: Oxford University Press, 1999, p.9.

20 Exploramos a questão da sensibilidade moderna na História do Brasil e de seu desenrolar na caracterização dos desdobramentos da história nacional em questão em: VARELLA, Flávia Florentino. Ver e tocar o passado: emoção 
brasileiros não constituíam uma sociedade comercial em vários aspectos. Aponta, por exemplo, a insuficiência das relações sociais, destacada na comparação feita entre a vivacidade e sociabilidade das senhoras espanholas e a apatia das portuguesas e brasileiras:

\begin{abstract}
A jovialidade dos americanos espanhóis, e particularmente das mulheres, que contrasta com a monótona gravidade dos portugueses, e dos seus descendentes brasileiros, atrai a atenção dos viajantes. No Brasil há muito poucas relações sociais, ainda mesmo entre amigos íntimos. As mulheres são retiradas em reclusão quase claustral, e tomam muito pequena parte na conversação da sociedade. Em Montevidéu e Buenos Aires pelo contrário, todas as noites são dedicadas ao teatro, ao baile ou tertúlia, ou à partida: nem a guerra, nem a revolução, nem a fome podem mudar a inclinação nacional a este respeito: daqui nasce a superior atração das senhoras espanholas. As suas maneiras são encantadoras, e ainda que imperfeitamente educadas, a sua conversação é cheia de espírito e da variedade. Não é portanto de admirar que este contraste tanto preponderasse sobre os oficiais brasileiros: acharam nas senhoras espanholas muitos atrativos, e mais acessivel sociabilidade do que jamais haviam experimentado nas suas patrícias, de modo que muitos casamentos se efetuaram, mesmo na expectativa de proximamente entrar em campanha. ${ }^{21}$
\end{abstract}

O contraste entre a educação feminina luso-brasileira e espanhola coloca em destaque uma espécie de herança portuguesa em que a convivência social e, por consequência, as conversações filosóficas, a dança, a música, entre tantas outras esferas do viver em sociedade foram marginalizadas. A criação de espaços de sociabilidade, como clubes e cafés, juntamente com a imprensa periódica, seriam importantes para o desenvolvimento da esfera pública social brasileira. ${ }^{22}$

Apesar de não contrapor diretamente o modo britânico e português de administração das colônias, Armitage apresenta o modelo britânico como comercial e dinâmico e, inversamente, o português como atrasado e estag-

e sentimento na História do Brasil de John Armitage. História da Historiografia, Ouro Preto, n.8, p.91-106, 2012.

21 ARMITAGE, João. História do Brasil: desde o período da chegada da família de Bragança, em 1808, até a abdicação de D. Pedro I, em 1831, compilada à vista dos documentos públicos e outras fontes originais formando uma continuação da História do Brasil de Southey. Belo Horizonte/São Paulo: Itatiaia/Edusp, 1981, p.132. Grifos nossos. No original: "The gaiety of the South American Spaniards, and particularly of the females, as contrasted with the monotonous gravity of the Portuguese and their Brazilian descendants, arrests in a remarkable degree the attention of every traveler. In Brazil there is but little social intercourse even amongst intimate friends. The women are retained in almost conventual seclusion, and have but little voice in society. In Monte Video and Buenos Ayres, on the contrary, every evening is dedicated either to the theatre, the ball, or the tertulia, or sirée; and neither war, nor revolution, nor famine, have as yet been able to change the national bias in this respect. Hence the superior attractions of the Spanish ladies. Their manners are in general fascinating; and though imperfectly educated, their conversation is replete with wit and variety. It cannot be surprising then, that the contrast should have had its weigh with the Brazilian officers. They found superior attractions among the Spanish ladies, and a greater facility of access to society than they had as yet experienced among their own countrywomen; and many marriages were the result even on the verge of an expected campaign." ARMITAGE, John. The History of Brazil: from the arrival of the Braganza family in 1808, to the abdication of Don Pedro the first in 1831. Compiled from State documents and others original sources. Forming a continuation to Southey's History of that country. v.1, London: Smith, Elder and Co., 1836, p.245.

22 Para um detalhamento desse processo no Brasil, vide MOREL, Marco. As transformações dos espaços públicos: imprensa, atores políticos e sociabilidades na cidade imperial (1820-1840). São Paulo: Hucitec, 2005. 
nado. Assim, para o autor, a expansão comercial seria uma das formas pelas quais a sociabilidade, gerada pela maximização do contato entre pessoas e coisas de diferentes partes do mundo, poderia ser cultivada pelos lusobrasileiros. No início de sua História do Brasil, Armitage resume o estado da sociedade luso-brasileira antes da chegada da Família Real, alegando:

No fim do século passado, a população podia ser estimada em cerca de três milhões e seiscentas mil almas, das quais dois quintos eram escravos, sendo a maior parte da gente livre uma raça mista de origem africana, índia e europeia; mas a branca continuou a ser a única a quem eram confiados os poderes políticos. É óbvio que não podia existir homogeneidade de ideias e de costumes em um povo composto de tantas castas; contudo, o caráter mais geral era aquele que facilmente se pôde calcular, segundo a natureza das instituições. Mantido pelo trabalho dos escravos, habitando um clima onde as produções da terra, são quase espontâneas, privado do estímulo e das ciências que a livre comunicação com as nações estrangeiras teria ministrado, era pela maior parte um povo indolente e apático. ${ }^{23}$

Para Armitage, a falta de estímulo no desenvolvimento das sociabilidades modernas resultaria na privação de uma sociedade comercial pelos habitantes do Brasil. ${ }^{24}$ Relata em sua História que, até o início do século XIX, não havia nenhuma tipografia ou universidade brasileira e a educação era extremamente precária. Além disso, um povo apático é um povo sem paixão. Considerando a reformulação da virtude pelo humanismo comercial, a paixão deixou de ser um vício para se constituir como virtude, desde que polida pelo comércio, formatada pela educação sentimental e transformada em maneiras.

Além da falta de estímulo à sociabilidade, Armitage também sinaliza, em diversos momentos, a existência de uma suposta inveja dos portugueses em relação aos avanços do Brasil, que impedia o desenvolvimento desta região e oprimia suas potencialidades. ${ }^{25}$ Existia uma diferença marcante entre o Brasil independente e o Brasil colônia, não apenas formulada na

23 ARMITAGE, João. História do Brasil, p.30. Grifos nossos. No original: "At the close of the last century, the population might be estimated at about three millions, six hundred thousands; of whom, about two-fifths were negro slaves. The majority of the free population were also a mixed race, derived jointly from African, Indian, and European origin; the white inhabitants being the only class as yet entrusted with political power. In the ideas and manners of a people comprising so many different castes, it is evident there could be but very little similarity; still their more general characteristics were in every respect such as might be anticipated from the nature of their institutions. Provided for by the labour of slaves, inhabitants of a climate where the productions of the earth are almost spontaneous, and devoid alike of the stimulus and the instruction, which must have resulted from a more unrestricted communication with foreigners, they were for the most part an indolent and apathetic race" ARMITAGE, John. The History of Brazil, v.1, p.8-9.

24 Armitage chega a registrar a "ausência de todos os dados de sociabilidade que podia se afirmar a não existência de uma opinião pública". Grifos do autor, cf. ARMITAGE, João. História do Brasil, p.31. No original: "and such was the absence of all the elements of sociability, that public opinion could not at this period be said to have any existence". ARMITAGE, John. The History of Brazil, v.1, p.10. Na passagem em inglês não aparece nenhum grifo.

25 As páginas em que os portugueses aparecem como tendo ciúme/inveja (jealousy) dos progressos do Brasil são: p.17, p.30, p.36, p.38 e p.41 da edição em português utilizada em todas as notas. Exceto na página 17 em que jealousy foi traduzido por "apreensões", todos os outros trechos constam como ciúme ou inveja. 
História do Brasil. Uma interpretação sobre o desenrolar da história nacional como oprimida por Portugal foi sendo construída principalmente após a proclamação das Cortes de Lisboa, quando instaurou-se a sensação entre os brasileiros de estarem regredindo do ponto de vista das liberalidades políticas e a mãe Portuguesa constantemente figurou como opressora deste que deveria ser o mais novo Império. Tanto o conceito de opressão foi largamente utilizado na luta política da Independência, quanto o de despotismo esteve associado à eliminação de um governo baseado em um sistema colonial que destruía a liberdade dos brasileiros. ${ }^{26}$

A história do Brasil e de Portugal apresentavam rasgos de ruptura por causa do fantasma do passado colonial e da recolonização. Sintoma dessa percepção foram os dois manifestos públicos divulgados por D. Pedro I pouco tempo antes da Independência. O primeiro deles, publicado em $1^{\circ}$ de agosto de 1822 e escrito por Joaquim Gonçalves Ledo, intitulava-se O Manifesto aos Povos do Brasil e justificava que foram as artimanhas da Corte de Lisboa que obrigaram os brasileiros a buscarem em D. Pedro I a figura de seu representante e garantidor de seus direitos. Essa situação apenas se concretizou visto que os legisladores portugueses extrapolaram suas funções ao se colocarem como soberanos de toda a monarquia portuguesa. O segundo pronunciamento público veio cinco dias depois, com o Manifesto às Nações Amigas, escrito por José Bonifácio, o qual ponderava a necessidade de ruptura com Portugal, mas dizia que, devido ao despotismo das Cortes de Lisboa, na insistência de retroceder ao sistema colonial antigo, o povo brasileiro via-se sem escolha. ${ }^{27}$ Poucos meses depois, poderia ser lido no periódico $O$ Espelho que o medo da recolonização pairava por causa da intransigência da Corte de Lisboa em exigir a volta de D. Pedro I para Portugal e tantas outras mudanças que relativizavam a singularidade brasileira. ${ }^{28}$ Diante da justificativa de que os brasileiros deveriam ser independentes, sob a proteção de D. Pedro I, para não haver uma recolonização, instaurou-se o discurso do passado colonial como despótico e opressor.

Este suposto estado de "colosso submisso, sem pretensões, e dependente de Portugal" 29 em que o Brasil encontrava-se antes de 1808, também teve sérias consequências para a metrópole na perspectiva de Armitage:

Semelhante a todas as dominações fundadas sobre a violência, o poderio português encerrava em si mesmo o germe de sua destruição. Além da aniquilação da sua nobreza, cuja aristocracia podia contrapesar a do clero, a demasiada extensão dos domínios exauriam as riquezas e a população da Metrópole; se

26 Apud NEVES, Lúcia Maria Bastos Pereira das. Corcundas e constitucionais: a cultura politica da independência (1820-1822). Rio de Janeiro: Revan, 2003, p.124-129.

27 NEVES, Lúcia Maria Bastos Pereira das. Corcundas e constitucionais, p.365-366

28 NEVES, Lúcia Maria Bastos Pereira das. Corcundas e constitucionais, p.370.

29 ARMITAGE, João. História do Brasil, p.31. No original: "colossal yet submissive and unaspiring dependency of Portugal”; ARMITAGE, John. The History of Brazil, v.1, p.12. 
os seus habitantes houvessem tido o comércio como objeto essencial, assim como o tinham os holandeses na mesma época, teriam podido enriquecer a Metrópole; mas desgraçadamente o espírito cavalheiresco era o que predominava, e a conquista era o fim primário a que se propunha com sacrifícios que agora parecem incríveis. ${ }^{30}$

A expansão portuguesa teria se preocupado mais com a exploração de partes diferentes do globo sob a preponderância de valores de uma sociedade medieval em desaparecimento, ao invés de renovar seus objetivos ao alimentar práticas de uma sociedade comercial. As consequências da postura cavalheiresca portuguesa refletiriam em todas as dimensões dessa sociedade, que abarcavam desde a literatura até o endividamento dos cofres públicos. Na visão de Armitage, grande parte da decadência portuguesa foi impulsionada pela junção entre expansão territorial e guerras religiosas na medida em que ambos os fatores contribuíram para a diminuição de sua dominação cultural ao desviar o foco do comércio para práticas associadas ao fanatismo religioso. ${ }^{31} \mathrm{~A}$ melhor solução para o Brasil, cogitava Armitage, era se desvincular do modo de gerenciamento português para, através do comércio e da interação com novos horizontes, chegar à tomada de consciência de que a sociedade cavalheiresca não deveria ser também seu destino.

\section{Pedro I e a sociedade (não) comercial}

O representante máximo português em solo brasileiro, D. Pedro I, parecia também não ter o comércio como um dos objetivos principais para o polimento de seus súditos. Principalmente por causa de seu envolvimento com a guerra da Cisplatina, Armitage caracterizou D. Pedro I como um monarca bélico e destituído das qualidades que o Brasil precisava naquele momento:

Elevado ao título de herói, durante a luta da Independência, parece ter sido guiado antes pelo exemplo de outros potentados, do que pela madura consideração do estado social, e das necessidades do Brasil: daí talvez a ansiedade com que se empenhou em uma guerra, que de certo teve a sua origem na agressão, e que, depois de acabrunhar o comércio, embaraçar o progresso dos melhoramentos, e exaurir as finanças do Brasil, terminou com a completa cessão da província

30 ARMITAGE, João. História do Brasil, p.169-170. Grifos nossos. No original: "Like all other empires based on violence, however, this of the Portuguese appears to have engendered within its own bosom the seeds of this overthrow. Independently of the annihilation of her nobility, whose aristocracy alone could balance that of the Clergy, the too extensive dominions of the mother country drained her alike of her riches and of her population. Had her inhabitants, like the Dutch at the same period, had chiefly a commercial object in view, they might possibly have enriched the parent State; but unfortunately, the 'spirit of chivalry' was far too rife amongst them, and conquest was the great and primary object, at a cost which at present appears almost incredible"; ARMITAGE, John. The History of Brazil, v.1, p.4-5.

31 Cf. ARMITAGE, João. História do Brasil, p.168-169; ARMITAGE, John. The History of Brazil, v.2, p.3-4. 
disputada. Nas circunstâncias que preponderavam no Brasil, quando D. Pedro subiu ao trono, carecia-se mais de um hábil administrador, do que um herói. ${ }^{32}$

A guerra, nesse sentido, não poderia trazer benefício algum ao Brasil, pelo contrário, esvaziava os cofres públicos e estagnava as atividades comerciais no país. A Guerra da Cisplatina, iniciada oficialmente contra Buenos Aires em 10 de dezembro de 1825 e que se estendeu até 27 de agosto de 1828, foi motivo de diversas críticas a D. Pedro I. Com o apoio de Buenos Aires e liderados por João Antonio Lavalleja e Fructuoso Rivera, a província da Cisplatina declarou sua independência do Brasil, resultando no início da guerra. Como teve uma colonização mais efetiva no período do domínio espanhol, seus habitantes herdaram tanto a língua quanto os costumes desse povo, motivo pelo qual a reincorporação desse território por D. João, em 1821, gerou tanto desconforto na região. ${ }^{33}$

O desfecho da guerra foi desastroso para o Brasil, pois não apenas perdeu parte de seu território com o acordo selado pelo governo britânico, que criou a República Oriental do Uruguai, mas também viu seus cofres em risco com as despesas da guerra. Tal envolvimento bélico brasileiro não recebera uma boa acolhida, na História do Brasil, por Armitage. A caracterização de $\mathrm{D}$. Pedro I como um monarca bélico foi um ponto negativo de sua personalidade, na medida em que preferiu dedicar-se a uma atividade que Armitage via como limitadora da sociedade comercial e dos benefícios que essa poderia trazer ao Brasil.

A personalidade de $D$. Pedro I certamente foi traçada de diversas formas dentro da historiografia brasileira oitocentista. Além dessa caracterização de Armitage, houve muitas outras que buscaram salientar sua pretensa tendência despótica. ${ }^{34} \mathrm{O}$ alemão Carl Seidler, por exemplo, definiu o monarca como um "Napoleão transatlântico, porém sem os louros da vitória", sendo "um dos personagens centrais do que o autor chamaria de uma 'mogiganga tragi-heróica', em que são descritas as desventuras da Guerra Cisplatina e os acontecimentos do Império de 1825 a 1835". ${ }^{35}$ Em outro contexto, foi comparado a Carlos X no que diz respeito às supostas tendências despó-

32 ARMITAGE, João. História do Brasil, p.226. Grifos nossos. No original: "Elevated into a hero during the struggle for independence, he appears to have been guided rather by the example of the other potentates, than by any mature consideration of the existing social state and necessities of Brazil; and hence, perhaps, the eagerness with which he embarked in a war, which had certainly its origin in aggression, and which, after crippling the commerce, checking the progress of improvement, and exhausting the finances of Brazil, ended only in a full and unrestricted cession of the province in dispute. Under the existing circumstances of Brazil, when Don Pedro ascended the throne, it was an administrator rather than a hero that was required"; ARMITAGE, John. The History of Brazil, v.2, p.136.

33 PIMENTA, João Paulo G. Estado e nação no fim dos impérios ibéricos no Prata (1808-1828). São Paulo: Hucitec/ Fapesp, 2002, p.215

34 Vale a pena salientar que no contexto dos primeiros anos da década de 1820 a figura de D. Pedro I ainda não era associada ao despotismo, pelo contrário, era tido como capaz de manter a "cena pública ordeira, sem violência ou distúrbios"; SOUZA, Iara Lis Carvalho. Pátria coroada: o Brasil como corpo político autônomo (1780-1831). São Paulo: Editora da UNESP, 1998, p.99.

35 LISBOA, Karen. Olhares estrangeiros sobre o Brasil no século XIX. In: MOTA, Carlos Guilherme. (org.). Viagem incompleta: a experiência brasileira. Formação: histórias. São Paulo: Senac São Paulo, 1999, p.274. 
ticas e absolutas de ambos, assim como, em outros momentos, também sofreu comparações nos mesmos termos com Bolívar e Fernando VII. ${ }^{36}$

O Brasil, na visão de Armitage, necessitaria de um governante que o reconhecesse como separado e diferente de Portugal em um sentido mais amplo, ou seja, o Brasil era dotado de peculiaridades que deveriam ser levadas em conta, para equiparar-se às demais nações civilizadas, e por civilizadas dever-se-ia entender sociedades comerciais. Aliado à não observância desses aspectos, havia um ponto fundamental que D. Pedro I não preenchia: ${ }^{37}$

Na verdade, nem o progresso da instrução, nem os esforços sediciosos do jornalismo, nem as irregularidades da vida privada de D. Pedro, eram a causa principal da sua impopularidade em todo o Império. Outra causa militava, além da má administração do Gabinete, causa de que nunca se fez menção, mas que todavia se fazia geralmente sentir: era nunca ter ele sabido ser o-HOMEM DO SEU POVO - nunca ter-se constituído inteira e verdadeiramente brasileiro. ${ }^{38}$

O Brasil e os brasileiros não poderiam ser encarados como uma parte, mesmo que desmembrada, de Portugal, pois existiam "peculiares necessidades, circunstâncias, e localidades do Brasil" que não deveriam ser negadas. ${ }^{39} \mathrm{~A}$ independência contribuiu sensivelmente para acentuar a diferença entre portugueses e brasileiros, uma vez que os portugueses eram tidos como a classe privilegiada, tanto do ponto de vista financeiro, quanto político, enquanto os brasileiros não obtinham o mesmo tipo de privilégios. ${ }^{40}$

Nestes primeiros anos de 1820, a identidade brasileira foi constantemente contraposta à portuguesa em diversas instâncias. Após a queda do ministério dos Andradas, "o partido andradista se viu totalmente isolado e se entrincheirou na imprensa para dar combate aos novos adversários, procurando insuflar na opinião pública um ânimo antilusitano". ${ }^{41}$ Nesse sentido, O Tamoio foi lançado menos de um mês após Bonifácio e seu irmão Martim Francisco terem saído de seus cargos. Claramente a favor dos Andradas,

36 MOREL, Marco. O período das Regências (1831-1840). Rio de Janeiro: Jorge Zahar, 2003, p.16-17.

37 É preciso destacar que tal interpretação de D. Pedro I como português e, com isso, oposto por princípio aos brasileiros e seus ideais foi constantemente utilizada pela historiografia moderada como justificativa da abdicação. Vide: PANDOLFI, Fernanda Cláudia. A abdicação de D. Pedro I: espaço público da política e opinião pública no final do Primeiro Reinado. São Paulo: Universidade Estadual Paulista, Campus de Assis, 2007, p.13 (História, Tese de doutorado).

38 ARMITAGE, João. História do Brasil, p.212-3. Grifos nossos. No original: "If the plain truth must be spoken, neither the progress of intelligence, nor the seditious efforts of the Journalists, nor the irregularities of the private life of Don Pedro, were the main cause of this own personal unpopularity throughout the entire Empire. For this there was another cause, apart also from the mal-administration of the Cabinet; a cause never openly alluded to, yet universally felt, and this was in his never having known how to become the MAN OF HIS PEOPLE, - in his never having constituted himself entirely and truly a Brazilian"; ARMITAGE, John. The History of Brazil, v.2, p.104.

39 ARMITAGE, João. História do Brasil, p.206. No original: "peculiar necessities, circumstances, or localities of Brazil"; ARMITAGE, John. The History of Brazil, v.2, p.87.

40 LUSTOSA, Isabel. Insultos impressos: a guerra dos jornais na Independência (1821-1823). São Paulo: Companhia das Letras, 2000, p.333-334.

41 LUSTOSA, Isabel. Insultos impressos, p.334-335. 
o periódico ganhou grande circulação, aumentando sua periodicidade em pouco tempo. Na terça-feira, 12 de agosto de 1823, O Tamoio, em sua primeira edição, denunciava os prejuízos da colonização portuguesa: "a sórdida avareza, o receio de perder tão rico tesouro, foi constantemente quem ditou as leis da sua administração, leis tirânicas, e absurdas, que em vez de prosperarem o nascente estabelecimento só tendiam a atrasá-lo, e a tirar-lhe as forças". ${ }^{42}$

A preponderância dos portugueses no governo era tida como uma estratégia absolutista de D. Pedro I e, após sua partida para Portugal, vista como tentativa de restauração da ordem anterior. ${ }^{43} \mathrm{O}$ partido caramuru, por exemplo, apesar de não desejar de forma homogênea a volta do monarca, sempre viu seu governo com certo saudosismo, chegando a cogitar que D. Pedro I poderia governar o Brasil durante a menoridade de seu filho. ${ }^{44}$

A crítica severa aos portugueses e ao Imperador teve início no começo de 1831. Para os liberais moderados, existiam os bons portugueses, ou "adotivos", que corroboravam com a causa nacional, e os maus, que buscavam a volta do Brasil ao estado de opressão colonial. Depois da Garrafada, esse discurso mudou e uma facção lusitana foi apresentada na Aurora Fluminense como tendo se instalado no Brasil após a Independência, no intuito de promover sua recolonização por meio do confronto entre adotivos e brasileiros. ${ }^{45}$

O embate entre portugueses e brasileiros, entre opressão e liberdade, despontava como uma possibilidade de entendimento da história nacional e uma saída para a afirmação do Brasil enquanto dotado de singularidades. É curioso notar as palavras de Antônio Carlos de Andrada e Silva quando defendia seu projeto de naturalização para os que não haviam nascido no Brasil. Alegava que nenhum português poderia "amar de coração uma ordem de coisas que implica na ruína de sua pátria de origem" e "se eu fosse português detestaria a separação e a Independência do Brasil". ${ }^{46}$ Desde a Independência e o sentimento antilusitano que se desenvolvia, a tensão causada pelo fato do Brasil ser governado por um português, D. Pedro I, como se nessa terra tivesse nascido, era latente e provavelmente só pôde ser solucionada com a abdicação em favor de um legítimo patriarca nacional: D. Pedro II. ${ }^{47}$

42 O Tamoio, n.1, p.2, 12 ago. 1823

43 RIBEIRO, Gladys Sabina. Causa nacional e cidadania: a participação popular e a autonomia na imprensa carioca no início dos anos 1830. In: NEVES, Lúcia Maria Bastos das; MOREL, Marco; FERREIRA, Tania Maria Bessone da C. (orgs.). História e imprensa: representações culturais e práticas de poder. Rio de Janeiro: DP\&A, 2006, p.121.

44 BASILE, Marcello. Projetos de Brasil e construção nacional na imprensa fluminense (1831-1835). In: NEVES, Lúcia Maria Bastos das; MOREL, Marco; FERREIRA, Tania Maria Bessone da C. (orgs.). História e imprensa, p.88.

45 RIBEIRO, Gladys Sabina. Causa nacional e cidadania, p.122.

46 NEVES, Lúcia M. B. P; MACHADO, Humberto Fernandes. O império do Brasil. Rio de Janeiro: Nova Fronteira, 1999, p.98.

47 A versão da incompatibilidade entre D. Pedro I e o Império do Brasil, na medida em que este representava o indesejável governo português, foi construída através do discurso liberal entre meados da década de 1820 até 


\section{Considerações finais}

Ao longo deste artigo buscamos demonstrar como a linguagem do humanismo comercial foi movimentada na História do Brasil, escrita por John Armitage, para dar forma à história nacional brasileira, ${ }^{48}$ principalmente no que diz respeito ao processo de independência brasileiro e, nesse sentido, passou de simples linguagem disponível para constituir-se como uma linguagem historiográfica em pleno funcionamento. Pontuamos dois momentos em que é possível observar essa incorporação de forma mais clara, sendo o primeiro deles na caracterização, feita por Armitage, de Portugal como um país atrasado e fora de sintonia com a agenda da insurgente sociedade comercial polida. Logo em seguida, apresentamos como foram incorporados aspectos da linguagem do humanismo comercial na caracterização da figura de D. Pedro I, quando Armitage atrela a personalidade do monarca brasileiro à tradição bélica portuguesa. D. Pedro I figura na narrativa como um símbolo da sociedade portuguesa e parece não permitir que o Brasil adentre em um novo regime histórico ligado ao progresso e ao comércio e que abandone o passado colonial português.

Ainda existem muitas lacunas e a necessidade de constantes pesquisas sistemáticas para podermos traçar um esboço mais preciso sobre os parâmetros historiográficos que nortearam a escrita da História do Brasil de John Armitage. Contudo acreditamos firmemente que esta primeira tentativa poderá colaborar para a discussão em torno das linguagens historiográficas que contribuíram para a formulação de certas interpretações da história nacional brasileira.

o desfecho final em 7 de abril de 1831, com a abdicação. Como bem demonstra lara Lis Carvalho Souza, tal incompatibilidade parece não ter existido nos primeiros anos do governo de D. Pedro I na medida em que ele contribuiu para a constituição de uma identidade política brasileira; cf. SOUZA, lara Lis Carvalho. Pátria coroada, passim.

48 Abordo, em outro momento, a recepção que a História do Brasil de Armitage teve no cenário brasileiro; vide: VARELLA, Flávia Florentino. A (im)possibilidade da escrita da história contemporânea: a História do Brasil de John Armitage e os brasileiros oitocentistas. In: SILVA, Ana Rosa Cloclet da; PEREIRA, Mateus; NICOLAZZI, Fernando. (orgs.). Contribuições à história da histografia luso-brasileira. São Paulo: Hucitec, 2012. 